\title{
Review Article \\ Prevalence and Risk Factors for Antenatal Depression in Ethiopia: Systematic Review
}

\author{
Wondale Getinet $\mathbb{D}^{1},{ }^{1}$ Tadele Amare $\mathbb{D}^{\mathbb{D}},{ }^{1}$ Berhanu Boru ${ }^{\mathbb{D}},{ }^{2}$ Shegaye Shumet, \\ Wubet Worku, ${ }^{2}$ and Telake Azale ${ }^{3}$ \\ ${ }^{1}$ Department of Psychiatry, College of Medicine and Health Science, University of Gondar, Gondar, Ethiopia \\ ${ }^{2}$ School of Nursing, College of Medicine and Health Science, University of Gondar, Gondar, Ethiopia \\ ${ }^{3}$ Public Health Institute, College of Medicine and Health Science, University of Gondar, Gondar, Ethiopia
}

Correspondence should be addressed to Wondale Getinet; wondale22@gmail.com

Received 17 February 2018; Revised 6 May 2018; Accepted 21 May 2018; Published 9 July 2018

Academic Editor: Janusz K. Rybakowski

Copyright (c) 2018 Wondale Getinet et al. This is an open access article distributed under the Creative Commons Attribution License, which permits unrestricted use, distribution, and reproduction in any medium, provided the original work is properly cited.

\begin{abstract}
Introduction. Antenatal depression is a syndrome, in which women experience depressed mood, excessive anxiety, insomnia, and change in weight during the period of pregnancy. Maternal depression negatively influences child outcomes and maternal health. Antenatal depression was measured by different rating scales, namely, BDI, EPDS, and PHQ. The objective of this systematic review was to synthesize logical evidence about the prevalence and potential risk factors of antenatal depression in Ethiopia. Methods. Our team explored multiple databases including PSYCHINFO, MEDLINE, Embase, Google Scholar, and Google Search to detect studies published with data on the prevalence of antenatal depression. We found 246 research papers on antenatal depression, of which 210 did not correspond to the title and 27 were duplicates. Subsequently, nine articles were used for synthesis prevalence, of which four studies were selected in the analysis of the effect of unplanned pregnancy on antenatal depression. Figures were extracted from published reports and grey literature, and any lost information was requested from investigators. Estimates were pooled using random-effects meta-analyses. Results. The pooled prevalence of antenatal depression for five studies selected, which had used BDI, was $25.33(20.74,29.92)$. The other four studies that had included other screening tools (3 EPDS and 1 PHQ) had the prevalence decreased to $23.56(19.04,28.07)$, and the pooled effect of unplanned pregnancy on antenatal depression was 1.93 (1.81, 2.06). Factors such as age, marital status, income, occupation, history of the previous mental disorder, antenatal follow-up, unplanned pregnancy, complication during to pregnancy, age of mother during pregnancy, conflict, and social support were associated with antenatal depression. Conclusions. Antenatal depression is a common maternal problem; further attention should be given to the effect of unplanned pregnancy, social support, pregnancy-related complications, family conflicts, and violence on pregnant women. All these are possible risk factors for antenatal depression.
\end{abstract}

\section{Background}

A global report by World Health Organization indicated that neuropsychiatric disorders represent a total of $28 \%$ of the diseases of which more than one-third are caused by depression [1]. Mental illness like depression, a cause of almost $12 \%$ of total years lived with disability worldwide [2], causes physical and psychological pain for both patients and caregivers [3]. Predictions show that depression becomes the second leading cause of disease burden by the year 2020 [4] and the leading cause of disability among women in childbearing age group, yet it does not remain a part of reproductive healthcare [5].

Pregnancy-related depression is the one encountered during the time of child conception. It is manifested by persistent sadness and associated with additional somatic symptoms like decreased energy, sleep disturbance, weight loss, hopelessness, difficulty to think, poor concentration, disturbed sleep, and trouble with appetite along with inability to feel happiness $[6,7]$.

Studies done in different countries showed that untreated antenatal depression in pregnant women has consequences 
TABLE 1: Prevalence of antenatal depression in different parts of the world.

\begin{tabular}{lcc}
\hline Country or town & Percentage of antenatal depression & Reference \\
\hline Brazil & $38 \%$ & {$[14]$} \\
\hline Sri Lanka & $16.2 \%$ & $15 \%$ \\
\hline Italy & $9.2 \%$ & {$[15]$} \\
\hline Mumbai & $12.3 \%$ & {$[16]$} \\
\hline India Bengaluru & $24.3 \%$ & {$[18]$} \\
\hline Oman & $59 \%$ & \\
\hline African American women (In low income category) & $27 \%$ & {$[19]$} \\
\hline Ukraine (HIV positive women) & $8.3 \%$, & {$[21]$} \\
\hline Nigeria & $24.5 \%$ & {$[22]$} \\
\hline Abeokuta Nigeria & $47 \%$ & {$[22]$} \\
\hline South Africa & $39 \%$ & {$[23]$} \\
\hline Cape Town & $38.8 \%$ & {$[24]$} \\
\hline Tanzania & $10 \%$ & {$[25]$} \\
\hline Ghana & $11.6 \%$ & {$[26]$} \\
\hline Malawi & $25 \%$ & \\
\hline Addis Ababa & {$[28]$} \\
\hline
\end{tabular}

on fetus like increased risk of preterm birth (PTB), low birth weight (LBW), intrauterine growth restriction (IUGR) [8], neurobehavioral development and adverse perinatal outcome like lower birth weight, childhood behavioral disturbance, difficulty in language development, unhealthy maternal behaviors, maternal impairment during the postpartum period, substance abuse, and decrease in parenting quality and effectiveness [6, 8-13].

Antenatal depression affects about 1/10 women in highincome countries $[29,30]$. It is a common public health problem in sub-Saharan Africa ranging from $8 \%$ to $40 \%$ [24, 31-33]. Many epidemiological findings worldwide have reported that depressive symptoms are more common during pregnancy than during the postpartum period [3437]. Depressive disorders after giving birth have a strong association with the depressive disorder during pregnancy [38-42].

Factors which can predispose women to antenatal depression are almost similar in different countries like unplanned pregnancy, physical health, financial situation, social life, educational status, poor antenatal follow-up, malnutrition, pregnancy-related complications, past history of mental disorder, and partner violence [18, 24, 25, 43].

Antenatal depression among Brazilian women indicated that the prevalence of depression in the third trimester of pregnancy was $38 \%$ and after delivery in the first six months was $43 \%$ [14]. The percentages of antenatal depression varied in other countries and regions of the world as indicated in Table 1.

The prevalence of antenatal depression in Ethiopia is different from one town to another; it ranges between $11.8 \%$ and 31.2 percent with almost $25 \%$ in Addis Ababa. The percentage in the rest of the towns in Ethiopia are: $23 \%$ in Gondar, 25.6\% in Shashemene, 28.7\% in Sodo district, 31.1\% in Maichew, $31.2 \%$ in Adama, $11.8 \%$ in Debretabor, $19.9 \%$ in Gilgel Gibe, and 17.9\% in Afar Dubti [28] (Table 1).
However, using different methodology and psychometric tools, an extensive variation was found among the prevalence rates of antenatal depression in Ethiopia as described by different investigators at different places and time. Such limited and discrepant logical information about antenatal depression in our country resulting from its disparity and backgrounds had not been systematically reviewed by health decision makers and implementers. Somewhat, until now no review has shown how to find target data in relation to pregnancy, socioeconomic, and demographic factors and to catch out the risk factors of antenatal depression.

The objective of this systematic review and meta-analysis was to make scientific evidence on the prevalence of antenatal depression and associated factors in Ethiopia. Is there an association between unplanned pregnancy and antenatal depression? Result of this study would benefit health organizers who have interest in formulating intervention strategies for antenatal depression in the native context.

\section{Methods}

2.1. Search Strategy. The protocol and writing of the results of this systematic review and meta-analysis were based on PRISMA guidelines [44]. A comprehensive literature search was done by entering the following titles in PubMed, MEDLINE, Cochrane Library, Embase, Google Scholar, and Google Search: "prevalence of antenatal depression in Ethiopia", "associated factors of antenatal depression in Ethiopia", "maternal depression in Ethiopia", and "pregnancy-related depression in Ethiopia". The Cochrane Library review database was also searched by the terms "prevalence of antenatal depression in Ethiopia" and "associated factors of antenatal depression in Ethiopia". Finally, we used MeSH terms and All terms words in MEDLINE and keywords in Embase. The titles and abstracts of all identified citations were screened for relevance and the full text of 


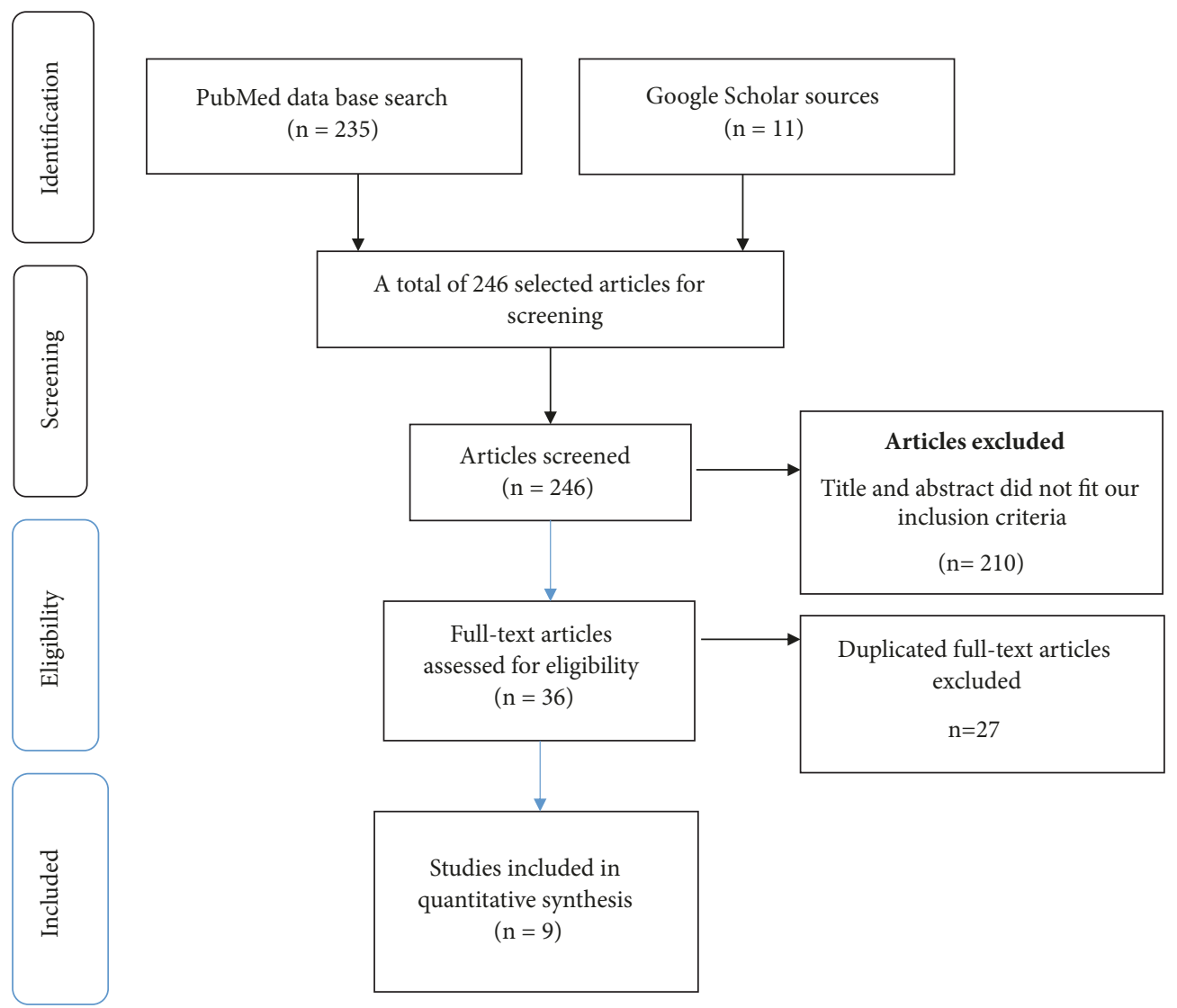

Figure 1: Flow chart of study selection.

potentially relevant articles was obtained and assessed for eligibility. No reviews could be found from Ethiopia.

2.2. Inclusion and Exclusion Criteria. As English is the language used in Ethiopia in the media and in higher institutions, articles not written in English were excluded from our study. In addition, articles which were not conducted in Ethiopia were also excluded. All publications of all years on the prevalence and associated factors of antenatal depression in Ethiopia were included in the study.

2.3. Critical Appraisal, Data Extraction, and Synthesis. The potentials of each systematic review were assessed by using a checklist adjusted from Joanna Briggs Institute (JBI) Critical Appraisal for Study Papers [45]. The checklist focuses on the following criteria: clearness of statement of objectives, the appropriateness of methodology, the appropriateness of research design, justification of selection strategy detail, appropriateness of data collection methods, the relationship between the researcher and the participant, consistency of data analysis, pure statement of findings, and discussion of the value of the research. The assessment of each of the studies in accordance with the checklist revealed that almost all of the reports were of acceptable quality. Data were primarily appraised for quality and then extraction was made using data extraction method. Data were analyzed using STATA V.14 statistical software. Due to the possibility of heterogeneity among the studies, random-effects meta-analysis models were preferentially reported. We developed the data extraction form that fits the specific objective of the systematic review. It included date of publication, name of the author, objective of the study, setting, study methods, and results. The data was initially assembled into themes like the prevalence of antenatal depression and associated factors. Meta-Analysis software was used to compute the pooled prevalence for the first five studies which used the same diagnostic tool Beck Depression Inventory (BDI) [46-50], the three which used Edinburgh Postnatal Depression Scale (EPDS) [28, 51, 52], and the one which used Patient Health Questionnaire (PHQ) [53]. Lastly, additional prevalence number was computed for the nine studies irrespective of the type of measuring tool they used for screening. At that time the report was made based on the themes.

2.4. Search Outcomes. The electronic searching of literature produced 246 articles: 210 did not fit the title, the abstract, and our inclusion criteria, and 27 were duplicates. Finally, nine articles were used for quantitative synthesis, four of which included the effect of unplanned pregnancy on antenatal depression (Figure 1).

2.5. Study Area and Settings. All studies were conducted in Ethiopia. There were no time restrictions during the database search. Seven of the studies were cross-sectional surveys and 


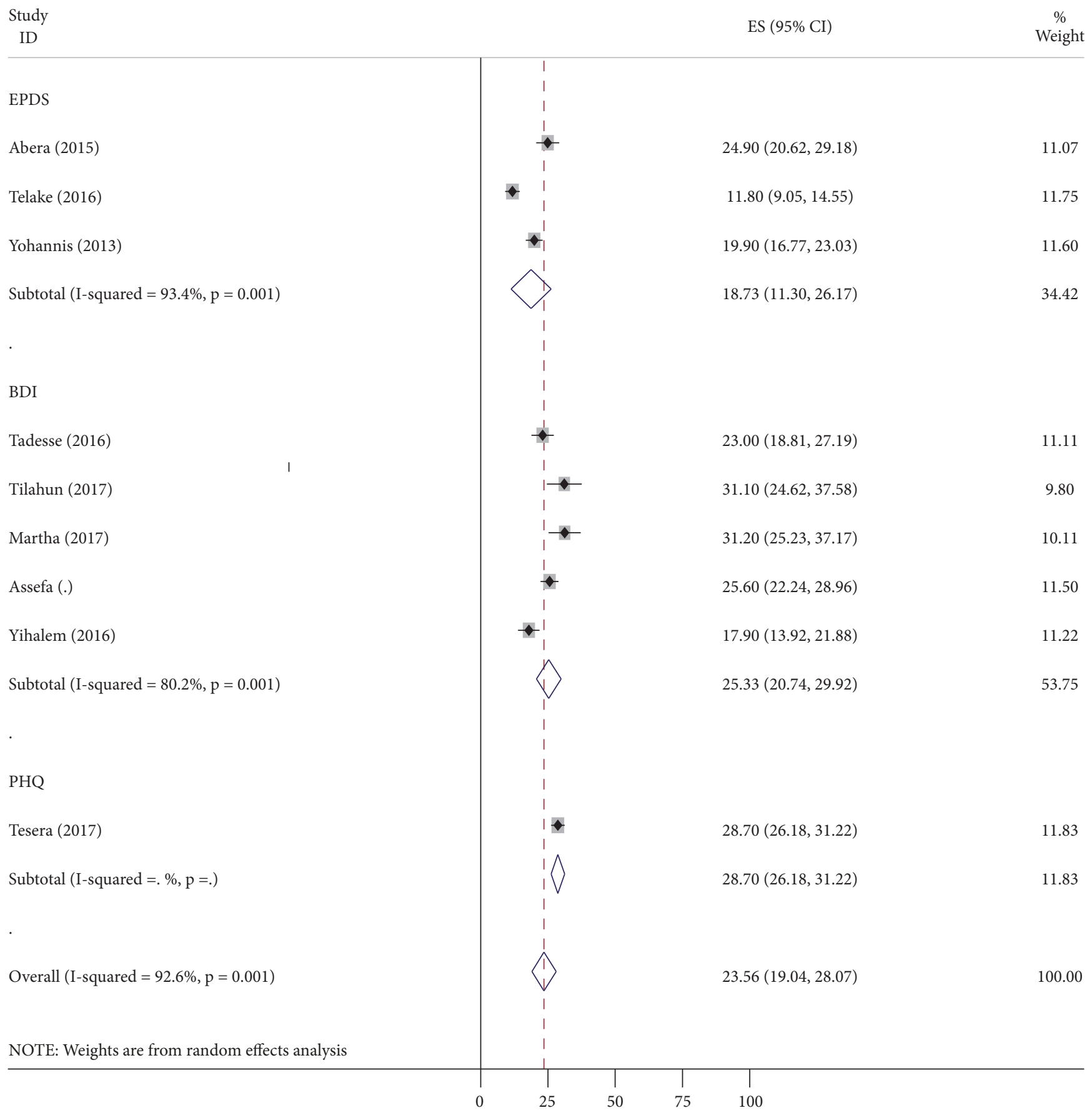

Figure 2

two were cohort study. No randomized controlled trials and case controls were obtained (Table 2).

\section{Results}

3.1. Antenatal Depression. Magnitude of antenatal depression in Ethiopia is between $11.8 \%$ and $31 \%$ [ $48,53,54]$. However, pooled prevalence of antenatal depression of five studies measured by BDI was $25.33(20.74,29.92)$ as shown in Figure 2. Still, pooled prevalence for the other three studies which used EPDS was $18.73(11.30,26.17)$. The prevalence rates in the nine studies used 5 BDI, 3 EPDS, and 1 PHQ. Pooled together, the prevalence was $23.56(19.04,28.07)$ (Figure 2).

3.2. Publication Bias. There was no evidence of bias upon inspection of funnel plots. However, due to the restricted number of studies included in the analysis, Egger's linear regression model was also used. The Egger's regression test for asymmetry suggested that there was no significant publication bias for the prevalence of antenatal depression 


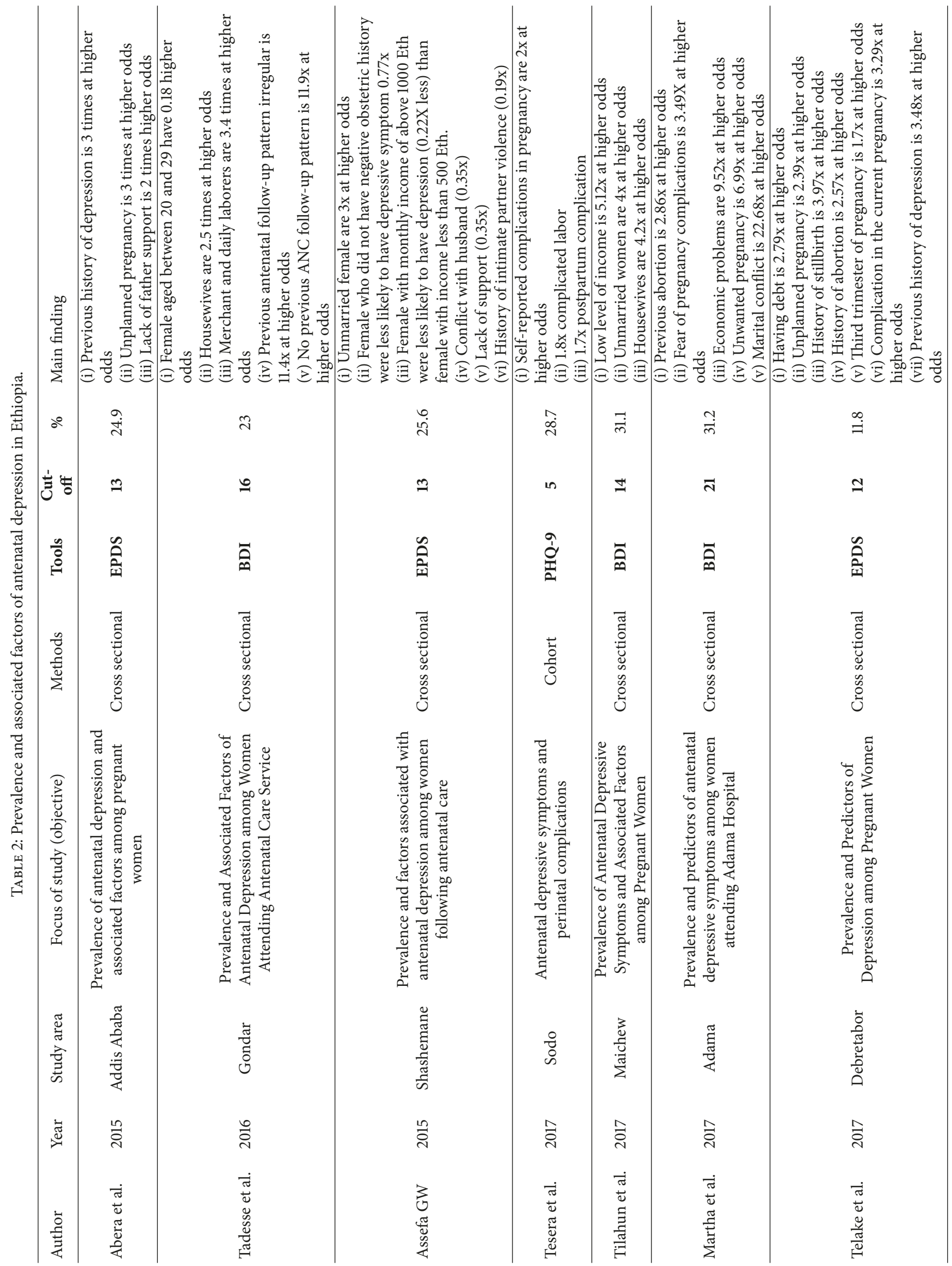




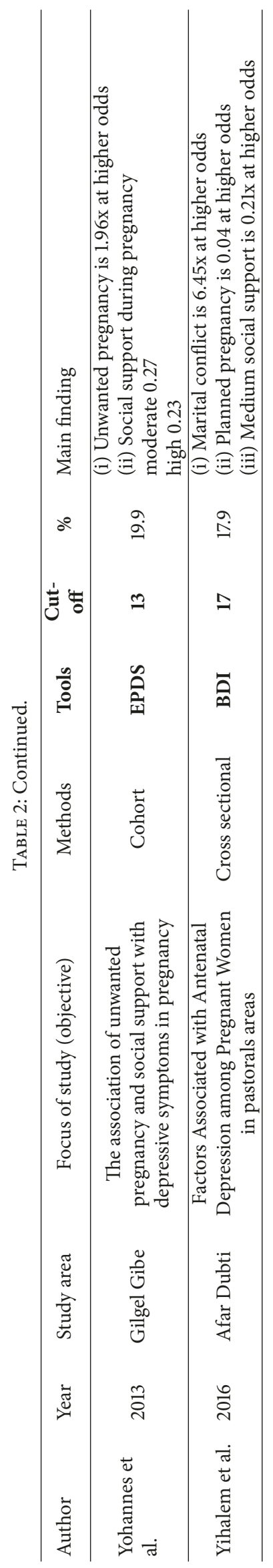




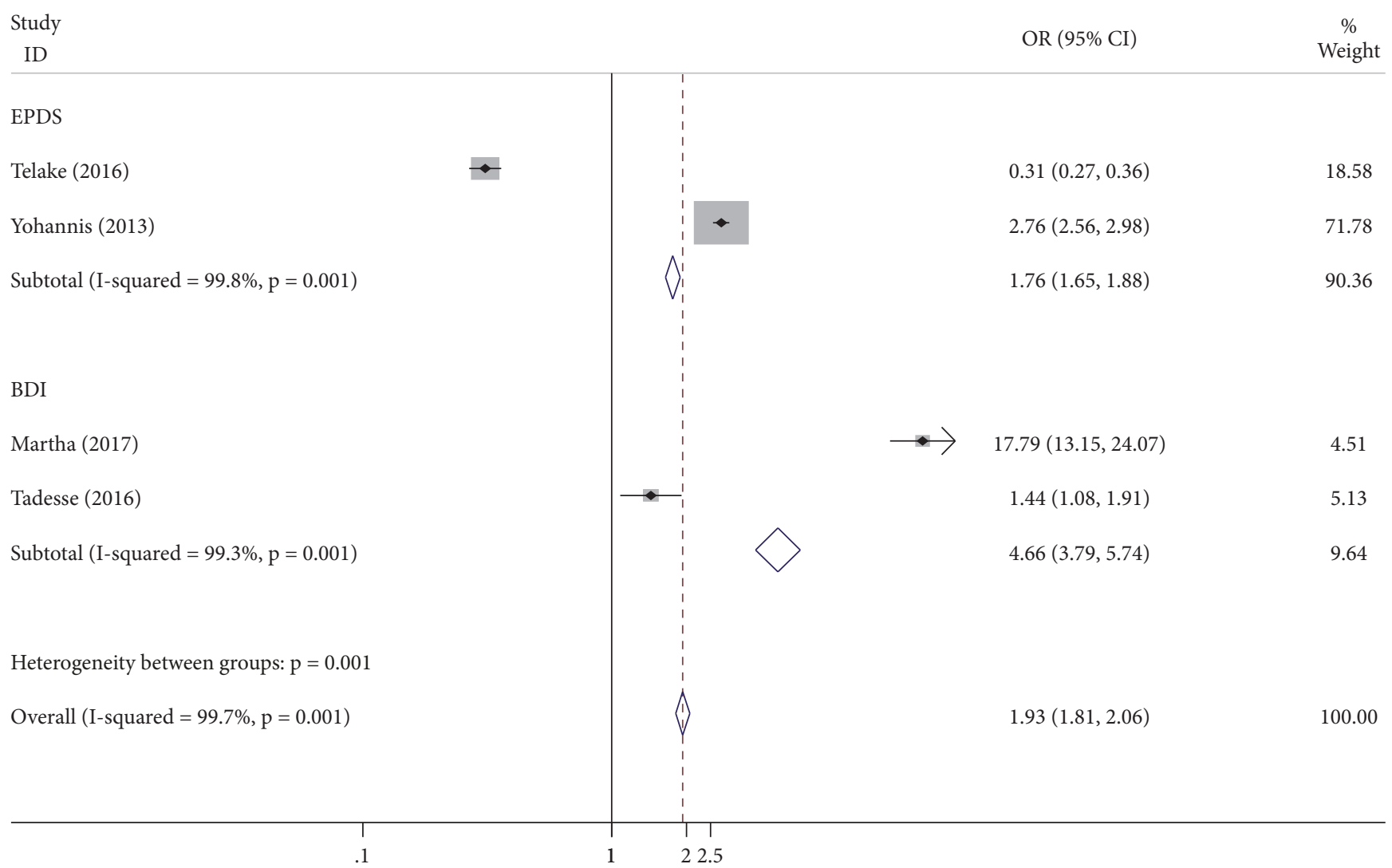

Figure 3: Pooled effect of unplanned pregnancy on antenatal depression in Ethiopia.

TABLE 3: Demographic risk factors of antenatal depression.

\begin{tabular}{|c|c|c|}
\hline $\begin{array}{l}\text { Demographic } \\
\text { Factors }\end{array}$ & Risks of demographic factors on antenatal depression & Author \\
\hline \multirow{2}{*}{ Marital Status } & Unmarried women have 4 times higher risk than married women & Tilahun et al., 2017 \\
\hline & Single women are $3 \mathrm{x}$ at higher odds than counter parts & Assefa GW, 2015 \\
\hline Age & $\begin{array}{c}\text { Women aged between } 20 \text { and } 29 \text { were } 72 \% \text { times less likely to develop } \\
\text { antenatal depression than those aged between } 14 \text { and } 19\end{array}$ & Tadesse et al., 2016 \\
\hline \multirow{3}{*}{ Occupation } & $\begin{array}{c}\text { Housewives are } 2.5 \mathrm{x} \text { more likely to have antenatal depression than } \\
\text { government employees }\end{array}$ & Tadesse et al., 2016 \\
\hline & $\begin{array}{c}\text { Merchant and daily laborers are } 3.4 \mathrm{x} \text { at higher odds than government } \\
\text { employees }\end{array}$ & Tadesse et al., 2016 \\
\hline & Housewives are $4.2 \mathrm{x}$ at higher odds than private workers & Tilahun et al., 2017 \\
\hline \multirow{4}{*}{ Income } & $\begin{array}{l}\text { Those with monthly income of above } 1000 \text { Eth. Birr are } 78 \% \text { less likely to } \\
\text { develop antenatal depression compared to those with income below } 500 \\
\text { Eth. Birr }\end{array}$ & Assefa GW, 2015 \\
\hline & $\begin{array}{l}\text { Income less than } 1500 \text { Eth. Birr is } 5.12 \mathrm{x} \text { at higher odds to develop } \\
\text { antenatal depression than income }>1500 \text { Eth. Birr. }\end{array}$ & Tilahun et al., 2017 \\
\hline & $\begin{array}{c}\text { Economic problems are } \begin{array}{c}9.52 \mathrm{x} \text { at higher odds to develop antenatal } \\
\text { depression }\end{array}\end{array}$ & Martha et al., 2017 \\
\hline & Having debt was 2.79x at higher odds to develop antenatal depression & Telake et al., 2017 \\
\hline
\end{tabular}

and effect of unplanned pregnancy $p=0.42, p=0.92$, respectively (Figures 2 and 3).

The prevalence of depression was high among pregnant women particularly in sub-Saharan Africa [24, 31-33]. All researchers tried to assess factors that lead pregnant women to antenatal depression (Tables 3 and 4). Concerning marital status women who were unmarried were more likely to be depressed than married mothers [47, 48]. However, women with age range between 20 and 29 were less likely to develop antenatal depression than women with age range between 14 
TABLE 4: Maternal risk factors for antenatal depression.

\begin{tabular}{|c|c|c|}
\hline Maternal Factor & Likelihood to develop antenatal depression & Author \\
\hline Mental disorder & $\begin{array}{l}\text { Previous history of depression is } 3 \mathrm{x} \text { and } 3.48 \mathrm{x} \text { at higher odds than no history of } \\
\text { depression }\end{array}$ & $\begin{array}{l}\text { Abera et al., 2015; } \\
\text { Telake et al., } 2017\end{array}$ \\
\hline \multirow{3}{*}{ Pregnancy related } & Unplanned pregnancy is $3 \mathrm{x}$ and 2.39 at higher odds than planned pregnancy & $\begin{array}{l}\text { Abera et al., 2015; } \\
\text { Telake et al., } 2017\end{array}$ \\
\hline & Unwanted pregnancy is $6.99 \mathrm{x}$ and $1.96 \mathrm{x}$ at higher odds than wanted pregnancy & $\begin{array}{l}\text { Martha et al., 2017; } \\
\text { Yohannis et al., } \\
2013\end{array}$ \\
\hline & $\begin{array}{l}\text { Women with planned pregnancy are } 96 \% \text { less likely to report depression than those } \\
\text { with unplanned pregnancy }\end{array}$ & Yihalem et al., 2016 \\
\hline \multirow[t]{2}{*}{ ANC follow-up } & $\begin{array}{l}\text { Previous irregular ANC follow-up is } 11.4 \mathrm{x} \text { at higher odds than regular ANC } \\
\text { follow-up }\end{array}$ & Tadesse et al., 2016 \\
\hline & No previous ANC follow-up is 11.9x at higher odds than those with ANC follow-up. & Tadesse et al., 2016 \\
\hline \multirow{7}{*}{$\begin{array}{l}\text { Pregnancy related } \\
\text { complications }\end{array}$} & $\begin{array}{l}\text { Women with no previous history of obstetric complications are } 23 \% \text { less likely to } \\
\text { have depressive symptoms. }\end{array}$ & Assefa GW, 2015 \\
\hline & Self-reported complications in pregnancy are $2 \mathrm{x}$ at higher odds & Tesera et al., 2017 \\
\hline & Fear of pregnancy complications is $3.49 \mathrm{X}$ at higher odds of depression & Martha et al., 2017 \\
\hline & $\begin{array}{l}\text { Complication in the current pregnancy is } 3.29 \mathrm{x} \text { at higher odds of depression than } \\
\text { absence of complication }\end{array}$ & Telake et al., 2017 \\
\hline & History of previous abortion is $2.86 \mathrm{x}$ at higher odds & Martha et al., 2017 \\
\hline & History of stillbirth is $3.97 \mathrm{x}$ at higher odds & Telake et al., 2017 \\
\hline & History of abortion is $2.57 \mathrm{x}$ at higher odds & Telake et al., 2017 \\
\hline Trimester & Pregnancies in the third trimester are $1.7 \mathrm{x}$ at higher odds than first trimester & Telake et al., 2017 \\
\hline \multirow{3}{*}{ Conflicts } & $\begin{array}{c}\text { Presence of conflicts with husband is } 0.35 \mathrm{x} \text { at higher odds to develop antenatal } \\
\text { depression }\end{array}$ & Assefa GW,2015 \\
\hline & $\begin{array}{c}\text { Presence of marital conflicts is } 22.68 \mathrm{x} \text { and } 6.45 \mathrm{x} \text { at higher odds to develop antenatal } \\
\text { depression }\end{array}$ & $\begin{array}{l}\text { Martha et al., 2017; } \\
\text { Yihalem et al., } 2016\end{array}$ \\
\hline & $\begin{array}{l}\text { History of intimate partner violence is } 0.19 \mathrm{x} \text { at higher odds to develop antenatal } \\
\text { depression }\end{array}$ & Assefa GW,2015 \\
\hline \multirow{3}{*}{ Social support } & Lack of father support is $2 \mathrm{x}$ at higher odds to develop antenatal depression & Abera et al., 2015 \\
\hline & Lack of support is $0.35 \mathrm{x}$ at higher odds to develop antenatal depression & Assefa GW, 2015 \\
\hline & $\begin{array}{c}\text { Women with moderate, medium and high social support during pregnancy are less } \\
\text { likely to report depressive symptoms ( } 0.27 \mathrm{x} \text { odds, } 0.21 \mathrm{x} \text { odds and } 0.23 \mathrm{x} \text { odds } \\
\text { respectively) }\end{array}$ & $\begin{array}{c}\text { Yohannis et al., } \\
2013\end{array}$ \\
\hline
\end{tabular}

and 19 [46]. Also, housewives compared to women who were concerned in government employment and private jobs were more likely to be depressed [46, 48]; additionally, merchant and daily laborers were at higher odds than government employees [46].

Pregnant women with a low income (monthly income of $<1500$ Eth. Birr) were more vulnerable to depression [48]; those with an income of above 1000 Eth. Birr were less likely to develop antenatal depression [47]. Moreover, women with money issues and debt have higher odds of depression [49, 54] (Table 3).

Women who had previous history of diagnosed depression were at higher odds of antenatal depression compared to women with no history of previous depression $[28,54]$. In more than half of the reviewed papers, pregnant women who had not planned their current pregnancy were more likely to have antenatal depression than those who had planned their pregnancy [28, 49-51, 54]. Pregnant women with irregular antenatal follow-up or no previous antenatal follow-up were at higher odds to develop depression [46]. Moreover, pregnant mothers with history of obstetric complications were more likely to develop antenatal depression in the majority of the reviewed papers (Table 4) compared to those with no previous history of obstetric complications [47]. Women who self-reported their complications during pregnancy [53], those who had the fear of complicated pregnancies [49], those with current complicated pregnancies [54], and those with history of abortion or stillbirth [49, 54] had all the predispositions to develop antenatal depression.

Women in third trimester of pregnancy have high risk to develop maternal depression [54]. Other factors like partner violence [47] and marital conflict [47, 49, 50] could cause antenatal depression. Social support helped pregnant women have less risk, while absence of social support contributed to the development of antenatal depression [28, 50, 51] (Table 4). 


\section{Discussion}

The aim of this systematic review and meta-analysis is to assess the effect of unplanned pregnancy and associated factors on the prevalence of antenatal depression. Diverse proportions of prevalence have been stated through different investigators, yet pooled prevalence of antenatal depression of nine studies was 23.56 (19.04, 28.07). It was similar to the prevalence reported in a cross-sectional study which was conducted in Gondar [46] and similar to study done in Addis Ababa and Shashemene [28, 47]. The pooled prevalence of antenatal depression suited the highest, i.e., 25.33 (20.74, 29.92), once BDI was used for screening, 28.7(19.04, 29.92) when PHQ was used, and 18.73 (11.30, 26.17) when EPDS was used. Psychometric tool used for measuring antenatal depression and cutoff point used to label the mother's depressive disorder are different from those used in the current review. Ahead of that, the study time and stage of pregnancy at which the data was collected could be considered as a source of expected variation between the current review and compared studies; the nature of psychometric tools used like $\mathrm{BDI}$ is liable to somatic symptoms when women are exposed to physical symptoms; when there is medical comorbidity, it may increase the value of depression with contrast to others.

The pooled prevalence of antenatal depression in nine studies (23\%) was also the same as the prevalence of antenatal depression in Asian and African countries like Oman and Nigeria $[19,22]$, respectively. The prevalence was similar to that of the global figure and represents the prevalence in the whole country as the samples were taken from various parts of Ethiopia. On the one hand, the pooled prevalence of antenatal depression in Ethiopia was lower than those in studies conducted in different countries like Brazil [14], America [20], Ukraine [21], South Africa [23], Cape Town [24], Tanzania [25], Sodo in Ethiopia [53], Maichew in Ethiopia [48], and Adama in Ethiopia [49]. On the other hand, the prevalence was higher than those in studies done in Sri Lanka [15], Italy [16], Mumbai [17], Bengaluru [18], Ghana [26], Malawi [27], Debretabor in Ethiopia [54], Gilgel Gibe in Ethiopia [51], and Afar Dubti in Ethiopia [50].

Antenatal depression was considerably higher among women who did not plan their current pregnancy. In almost more than half of the papers reviewed, unplanned or unwanted pregnancy was the factor leading to antenatal depression compared to planned pregnancy [28, 49-51, 54]. The pooled effect of unplanned pregnancy on antenatal depression was $1.93(1.81,2.06)$. Unplanned pregnancy might have some influence on depression causing physical, psychological, and social changes in women.

The other factor that had a significant association with maternal depression was marital status of women. Unmarried women have a higher rate of prevalence for antenatal depression than married ones $[47,48]$. The reason could be that unmarried women might practice more loneliness, poorer social support, and lower self-confidence and are more likely to be living alone, which are usually regarded as risk factors for depression in the pregnant women.

In our review, monthly family income of pregnant mothers was an important variable that holds huge share in antenatal depression $[47-49,54]$.This indicated that pregnant mothers with low income, with debt, and with economic problems are more likely to develop antenatal depression than those who have no debt with medium and high monthly domestic income. The reason could be that low income decreases the likelihood of independent living and increases the psychosocial stress of life in pregnant women, the worry of future mother about the newborn baby, and the financial struggle they might encounter after the birth.

As previously described, women occupation was significantly associated with antenatal depression, for example, nongovernmental employment, being merchant or daily laborer, and being a housewife $[46,48]$. The fear of being financially dependent on others or financially not sufficient could be the reason for the potential to develop antenatal depression. Relationship between socioeconomic factors and antenatal depression requires additional research; it contradicts the findings in developed nations where the prevalence of depression was comparatively higher in high-income countries than in developing countries.

Women with previous history of depression were more likely to develop depression during pregnancy. Those women might be more biologically vulnerable due to the hormonal changes during pregnancy. The hormonal changes together with their psychological and social situation will increase their susceptibility to depression development and exposure to recurrent depression $[28,54]$. Previous history of obstetric complications was reported to be a risk factor for developing antenatal depression $[47,49,53,54]$. It might be a psychological fear of having another complication in the current pregnancy. Conflict with husband and partner violence are other risk factors causing antenatal depression $[47,49,50]$. Other factors such as age, antenatal follow-up, age of pregnancy, and social support have consistently an impact on antenatal depression. These results were similar with studies carried out in the developed countries. The results of the review suggest common risk factors of developing antenatal depression worldwide. Antenatal depression is present in most countries irrespective of the ethnic origin. The prevalence of antenatal depression in Ethiopia is comparatively higher than other countries. This result has effects for policy makers, health administrators, professionals, and the community. This finding provides evidence on prevalence of antenatal depression on Ethiopian women with locally relevant data, where antenatal depression may negatively influence mother-infant health outcomes. Actions to reduce the effect of antenatal depression should be taken, and these priority areas must be considered: awareness, family contribution, prevention and early intervention, and support of the primary healthcare system. Intervention studies that evaluate current and previous policy initiatives and the wider impacts of health system strengthening on antenatal depression and outcomes should be a focused priority.

National intervention plans should focus on resolving conflicts and intimate partner violence, giving social support, and counseling on the age of women to get pregnant and their marital status. These are the key risk factors leading to antenatal depression. However, due to shortage of available and indexed articles about antenatal depression in Ethiopia, 
the review was conducted on only the current limited literature. Therefore, the prevalence of antenatal depression reported here was an estimation rather than an exact number.

\section{Conclusions}

Antenatal depression is a common maternal and public health problem; further attention should be given to unplanned pregnancy, social support, pregnancy-related complications, conflicts, and household violence. A proper obstetric and maternal care in women as well as a routine screening of women in the antenatal period may decrease the prevalence of depression during pregnancy.

\section{Abbreviations}

ANC: Antenatal care

BDI: Beck depression inventory

EPDS: Edinburgh postnatal depression scale

IUGR: Intrauterine growth restriction

LBW: Lower birth weight

PTB: Preterm birth

PHQ: Patient health questionnaire

WHO: World Health Organization.

\section{Conflicts of Interest}

The authors declare that they have no conflicts of interest.

\section{Authors' Contributions}

Wondale Getinet had a primary role in conceptualization, data review, data extraction, and data analysis. Tadele Amare had a role in data review and data extraction. All the authors have contributed to the writing and editing of this manuscript and have read and approved the final version.

\section{Acknowledgments}

The authors would like to thank their friends for their tireless gratitude and honest support while preparing this review. They also thank Dr. Sihem Aouabdi, KAIMRC, KSA, for editing the paper on behalf of Science Edit for the Developing World.

\section{References}

[1] World Health Organization, The World Health Report 2001: Mental health: new understanding, new hope, World Health Organization, 2001.

[2] V. Patel, M. Rodrigues, and N. DeSouza, "Gender, poverty, and postnatal depression: a study of mothers in Goa, India," The American Journal of Psychiatry, vol. 159, no. 1, pp. 43-47, 2002.

[3] Depression W, “A global Crisis," World Mental Health Day, 2012.

[4] FMOH, "National Mental Health Strategy of Ethiopia :(2012/13 -2015/16)," Addis Ababa, 2012.

[5] World Health Organization, Fund UNP, and Society KCfWsHi, Mental health aspects of women's reproductive health: a global review of the literature, World Health Organization, 2009.

[6] L. Bonari, N. Pinto, E. Ahn, A. Einarson, M. Steiner, and G. Koren, "Perinatal risks of untreated depression during pregnancy," The Canadian Journal of Psychiatry, vol. 49, no. 11, pp. 726-735, 2004.

[7] V. Sharma and C. J. Pope, "Pregnancy and bipolar disorder: A systematic review," Journal of Clinical Psychiatry, vol. 73, no. 11, pp. 1447-1455, 2012.

[8] N. K. Grote, J. A. Bridge, A. R. Gavin, J. L. Melville, S. Iyengar, and W. J. Katon, "A meta-analysis of depression during pregnancy and the risk of preterm birth, low birth weight, and intrauterine growth restriction," Archives of General Psychiatry, vol. 67, no. 10, pp. 1012-1024, 2010.

[9] M. T. Kinsella and C. Monk, "Impact of maternal stress, depression and anxiety on fetal neurobehavioral development," Clinical Obstetrics and Gynecology, vol. 52, no. 3, pp. 425-440, 2009.

[10] C. Dunkel Schetter and L. Tanner, "Anxiety, depression and stress in pregnancy: implications for mothers, children, research, and practice," Current Opinion in Psychiatry, vol. 25, no. 2, pp. 141-148, 2012.

[11] A. D. Cox, "Maternal depression and impact on children's development," Archives of Disease in Childhood, vol. 63, no. 1, pp. 90-95, 1988.

[12] A. Rahman, J. Bunn, H. Lovel, and F. Creed, "Association between antenatal depression and low birthweight in a developing country," Acta Psychiatrica Scandinavica, vol. 115, no. 6, pp. 481-486, 2007.

[13] B. Gelaye, M. B. Rondon, R. Araya, and M. A. Williams, "Epidemiology of maternal depression, risk factors, and child outcomes in low-income and middle-income countries," The Lancet Psychiatry, vol. 3, no. 10, pp. 973-982, 2016.

[14] P. Snaith, "What do depression rating scales measure?" The British Journal of Psychiatry, vol. 163, pp. 293-298, 1993.

[15] S. B. Agampodi and T. C. Agampodi, "Antenatal Depression in Anuradhapura, Sri Lanka and the Factor Structure of the Sinhalese Version of Edinburgh Post Partum Depression Scale among Pregnant Women," PLoS ONE, vol. 8, no. 7, Article ID e69708, 2013.

[16] F. Agostini, E. Neri, P. Salvatori, S. Dellabartola, L. Bozicevic, and F. Monti, "Antenatal Depressive Symptoms Associated with Specific Life Events and Sources of Social Support Among Italian Women," Maternal and Child Health Journal, vol. 19, no. 5, pp. 1131-1141, 2015.

[17] S. Ajinkya, P. Jadhav, and N. Srivastava, "Depression during pregnancy: prevalence and obstetric risk factors among pregnant women attending a tertiary care hospital in Navi Mumbai," Industrial Psychiatry Journal, vol. 22, no. 1, pp. 37-40, 2013.

[18] A. D. Bavle, A. S. Chandahalli, A. S. Phatak, N. Rangaiah, S. M. Kuthandahalli, and P. N. Nagendra, "Antenatal depression in a tertiary care hospital," Indian Journal of Psychological Medicine, vol. 38, no. 1, pp. 31-35, 2016.

[19] M. Al-Azri, I. Al-Lawati, R. Al-Kamyani et al., "Prevalence and risk factors of antenatal depression among Omani women in a primary care setting: Cross-sectional study," Sultan Qaboos University Medical Sciences Journal, vol. 16, no. 1, pp. e35-e41, 2016.

[20] J. L. Alhusen, L. Ayres, and K. Depriest, "Effects of Maternal Mental Health on Engagement in Favorable Health Practices During Pregnancy," Journal of Midwifery \& Women's Health, vol. 61, no. 2, pp. 210-216, 2016.

[21] H. Bailey, R. Malyuta, I. Semenenko, C. L. Townsend, M. Cortina-Borja, and C. Thorne, "Prevalence of depressive symptoms in pregnant and postnatal HIV-positive women in Ukraine: A cross-sectional survey," Reproductive Health, vol. 13, no. 1, article no. 150, 2016. 
[22] O. Thompson and I. Ajayi, "Prevalence of Antenatal Depression and Associated Risk Factors among Pregnant Women Attending Antenatal Clinics in Abeokuta North Local Government Area, Nigeria," Depression Research and Treatment, vol. 2016, Article ID 4518979, 2016.

[23] T. J. Rochat, M. Tomlinson, T. Bärnighausen, M.-L. Newell, and A. Stein, "The prevalence and clinical presentation of antenatal depression in rural South Africa," Journal of Affective Disorders, vol. 135, no. 1-3, pp. 362-373, 2011.

[24] M. Hartley, M. Tomlinson, E. Greco et al., "Depressed mood in pregnancy: Prevalence and correlates in two Cape Town periurban settlements," Reproductive Health, vol. 8, no. 9, 2011.

[25] M. Rwakarema, S. S. Premji, E. C. Nyanza, P. Riziki, and L. Palacios-Derflingher, "Antenatal depression is associated with pregnancy-related anxiety, partner relations, and wealth in women in Northern Tanzania: A cross-sectional study," BMC Women's Health, vol. 15, no. 1, article no. 68, 2015.

[26] B. Weobong, A. H. A. Ten Asbroek, S. Soremekun et al., "Association of antenatal depression with adverse consequences for the mother and newborn in rural Ghana: Findings from the DON population-based cohort study," PLoS ONE, vol. 9, no. 12, Article ID el16333, 2014.

[27] R. C. Stewart, E. Umar, B. Tomenson, and F. Creed, "A crosssectional study of antenatal depression and associated factors in Malawi," Archives of Women's Mental Health, vol. 17, no. 2, pp. 145-154, 2014.

[28] A. Biratu and D. Haile, "Prevalence of antenatal depression and associated factors among pregnant women in Addis Ababa, Ethiopia: a cross-sectional study," Reproductive Health, vol. 12, article 99, 2015.

[29] V. Hendrick, L. Altshuler, L. Cohen, and Z. Stowe, "Evaluation of mental health and depression during pregnancy," Psychopharmacology Bulletin, vol. 34, pp. 297-299, 1998.

[30] H. Bennett, A. Einarson, A. Taddio, G. Koren, and T. Einarson, "The American College of Obstetricians and Gynecologists," Systematic Review, vol. 103, no. 4, 2004.

[31] J. L. Cox, "Psychiatric morbidity and pregnancy: A controlled study of 263 semi-rural Ugandan women," The British Journal of Psychiatry, vol. 134, no. 4, pp. 401-405, 1979.

[32] O. A. Abiodun, O. O. Adetoro, and O. O. Ogunbode, "Psychiatric morbidity in a pregnant population in Nigeria," General Hospital Psychiatry, vol. 15, no. 2, pp. 125-128, 1993.

[33] A. O. Adewuya, B. A. Ola, O. O. Aloba, A. O. Dada, and O. O. Fasoto, "Prevalence and correlates of depression in late pregnancy among Nigerian women," Depression and Anxiety, vol. 24, no. 1, pp. 15-21, 2007.

[34] J. Evans, J. Heron, H. Francomb, S. Oke, and J. Golding, "Cohort study of depressed mood during pregnancy and after childbirth," British Medical Journal, vol. 323, no. 7307, pp. 257260, 2001 .

[35] I. H. Gotlib, V. E. Whiffen, J. H. Mount, K. Milne, and N. I. Cordy, "Prevalence rates and demographic characteristics associated with depression in pregnancy and the postpartum," Journal of Consulting and Clinical Psychology, vol. 57, no. 2, pp. 269274, 1989.

[36] V. O'Keane and M. S. Marsh, "Depression during pregnancy," BMJ, vol. 334, no. 7601, pp. 1003-1005, 2007.

[37] H. A. Bennett, A. Einarson, A. Taddio, G. Koren, and T. R. Einarson, "Prevalence of depression during pregnancy: systematic review, Obstetrics \& Gynecology, vol. 103, no. 4, pp. 698709, 2004.
[38] J. Heron, T. G. O'Connor, J. Evans, J. Golding, and V. Glover, "The course of anxiety and depression through pregnancy and the postpartum in a community sample," Journal of Affective Disorders, vol. 80, no. 1, pp. 65-73, 2004.

[39] D. Da Costa, J. Larouche, M. Dritsa, and W. Brender, "Psychosocial correlates of prepartum and postpartum depressed mood," Journal of Affective Disorders, vol. 59, no. 1, pp. 31-40, 2000.

[40] M. Pajulo, E. Savonlahti, A. Sourander, H. Helenius, and J. Piha, "Antenatal depression, substance dependency and social support," Journal of Affective Disorders, vol. 65, no. 1, pp. 9-17, 2001.

[41] S. Misri, K. Kendrick, T. F. Oberlander et al., "Antenatal depression and anxiety affect postpartum parenting stress: A longitudinal, prospective study," The Canadian Journal of Psychiatry, vol. 55, no. 4, pp. 222-228, 2010.

[42] E. Yazici, T. S. Kirkan, P. A. Aslan, N. Aydin, and A. B. Yazic, "Untreated depression in the first trimester of pregnancy leads to postpartum depression: High rates from a natural follow-up study," Neuropsychiatric Disease and Treatment, vol. 11, pp. 405411, 2015.

[43] S. Ajinkya, R. J. Pradeep, and N. S. Nimisha, "Risk factors predispose to depression during pregnancy," Industrial Psychiatry Journal, vol. 22, pp. 37-40, 2013.

[44] D. Moher, A. Liberati, and J. Tetzlaff, "Preferred reporting items for systematic reviews and meta-analyses: the PRISMA statement," Journal of Clinical Epidemiology, vol. 62, no. 10, pp. 10061012, 2009.

[45] E. Aromataris, R. Fernandez, C. M. Godfrey, C. Holly, H. Khalil, and P. Tungpunkom, "Summarizing systematic reviews: Methodological development, conduct and reporting of an umbrella review approach," International Journal of EvidenceBased Healthcare, vol. 13, no. 3, pp. 132-140, 2015.

[46] T. A. Ayele, T. Azale, K. Alemu, Z. Abdissa, H. Mulat, and A. Fekadu, "Prevalence and associated factors of antenatal depression among women attending antenatal care service at gondar university hospital, northwest Ethiopia," PLoS ONE, vol. 11, no. 5, Article ID e0155125, 2016.

[47] W. Assefa Gemta, "Prevalence and factors associated with antenatal depression among women following antenatal care at Shashemane health facilities, South Ethiopia," Annals of Global Health, vol. 81, no. 1, p. 90, 2015.

[48] T. B. Mossie, A. K. Sibhatu, A. Dargie, and A. D. Ayele, "Prevalence of antenatal depressive symptoms and associated factors among pregnant women in Maichew, North Ethiopia: an institution based study," Ethiopian Journal of Health Sciences, vol. 27, no. 1, pp. 59-66, 2017.

[49] A. S. Martha, T. S. Mesfin, A. Tadese, and B. Dessalegn, "Prevalence and predictors of antenatal depressive symptoms among women attending Adama Hospital Antenatal Clinic, Adama, Ethiopia," International Journal of Nursing and Midwifery, vol. 9, no. 5, pp. 58-64, 2017.

[50] A. Yihalem, K. Kassahun, F. Fetuma, and L. Misgan, "Factors Associated with Antenatal Depression among Pregnant Women in pastorals areas," Northeastern Ethiopia, [In press].

[51] Y. Dibaba, M. Fantahun, and M. J. Hindin, "The association of unwanted pregnancy and social support with depressive symptoms in pregnancy: evidence from rural Southwestern Ethiopia," BMC Pregnancy and Childbirth, vol. 13, article 135, 2013.

[52] B. Azeze, M. Fantahun, G. Kidan, and T. Haile, "Seroprevalence of syphilis amongst pregnant women attending antenatal clinics 
in a rural hospital in north west Ethiopia," Genitourinary Medicine, vol. 71, no. 6, pp. 347-350, 1995.

[53] T. Bitew, C. Hanlon, E. Kebede, S. Honikman, and A. Fekadu, "Antenatal depressive symptoms and perinatal complications: A prospective study in rural Ethiopia," BMC Psychiatry, vol. 17, no. 1, article 301, 2017.

[54] T. A. Bisetegn, G. Mihretie, and T. Muche, "Prevalence and predictors of depression among pregnant women in debretabor town, northwest Ethiopia," PLoS ONE, vol. 11, no. 9, Article ID e0161108, 2016. 


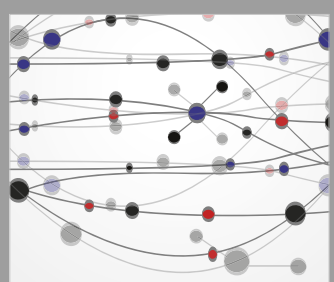

The Scientific World Journal
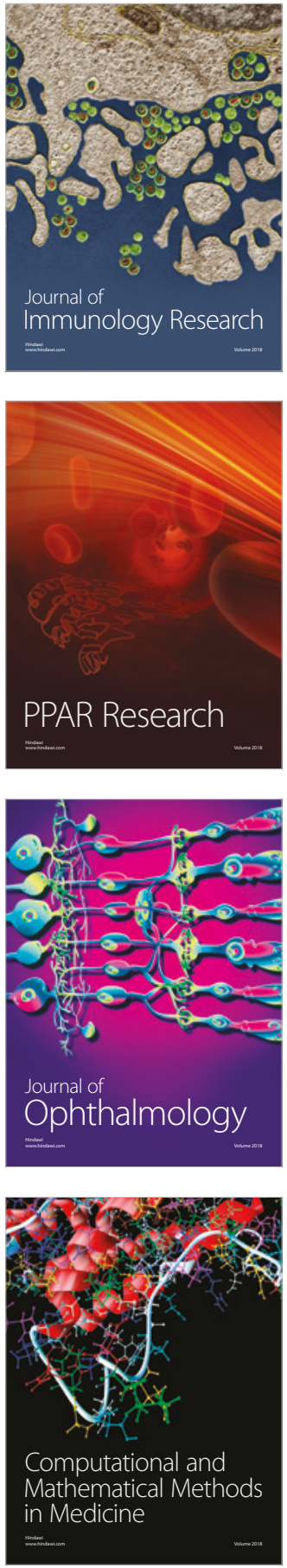

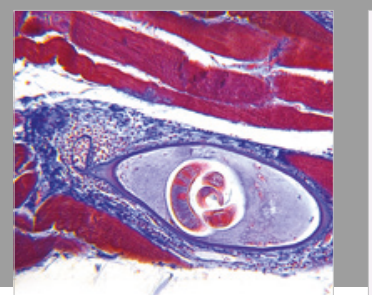

Gastroenterology Research and Practice

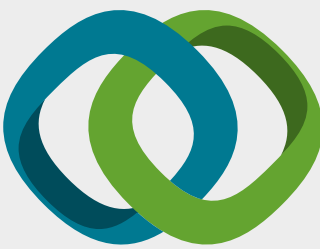

\section{Hindawi}

Submit your manuscripts at

www.hindawi.com
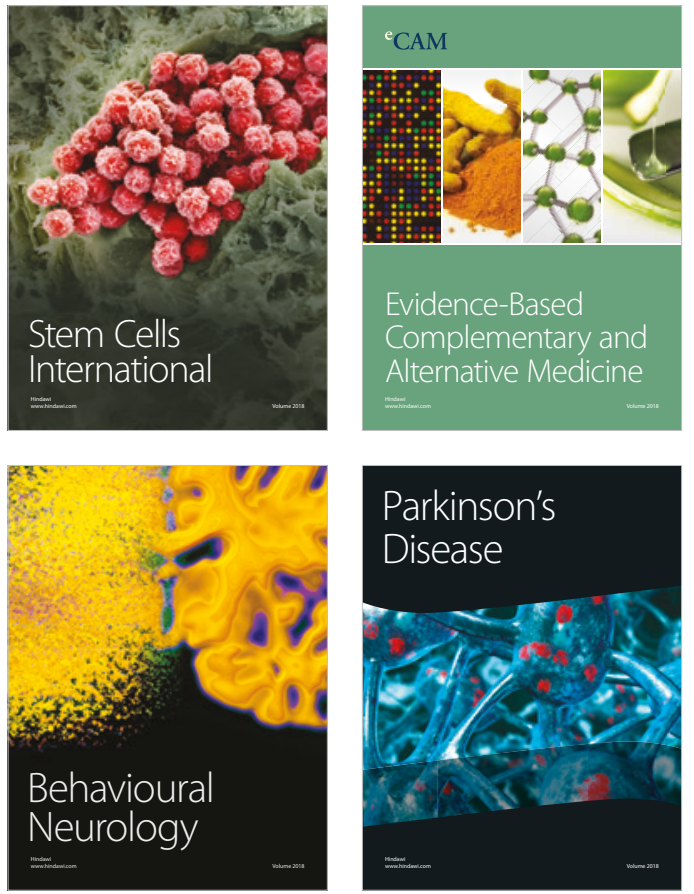

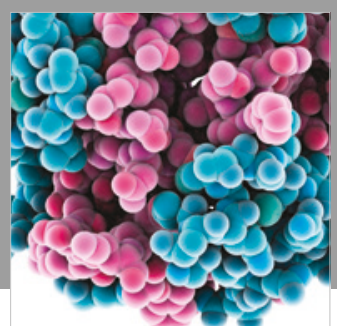

ournal of

Diabetes Research

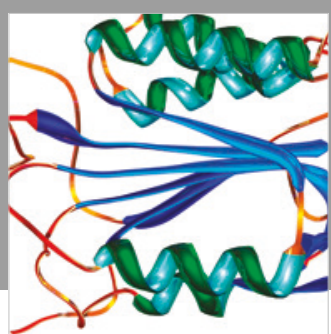

Disease Markers
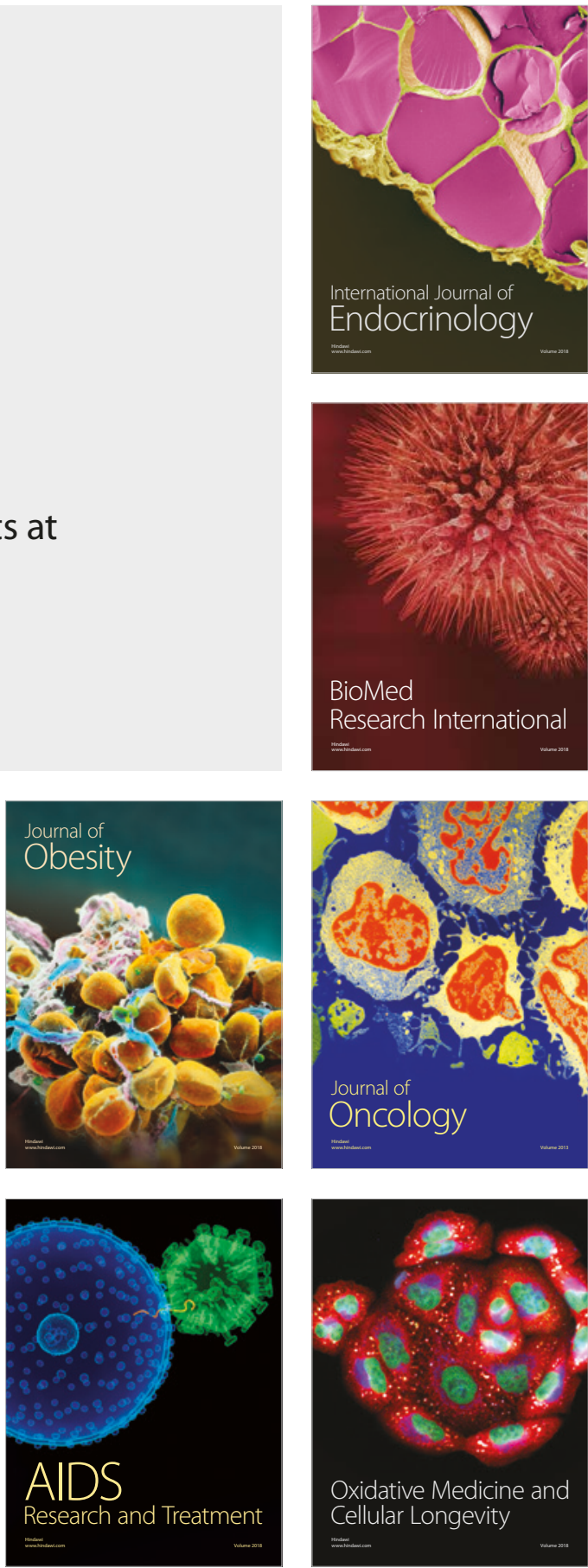